\title{
Subcellular Distribution of Cadmium in Two Paddy Rice Varieties with Different Cooking Methods
}

\author{
Bo-Ching Chen, Hung-Yu Lai \\ Department of Post-Modern Agriculture, MingDao University, Taiwan \\ Email:soil.lai@mdu.edu.tw
}

Received 6 June 2016; accepted 21 June 2016; published 24 June 2016

Copyright (C) 2016 by authors and Scientific Research Publishing Inc.

This work is licensed under the Creative Commons Attribution International License (CC BY). http://creativecommons.org/licenses/by/4.0/

(c) (i) Open Access

\begin{abstract}
Cadmium (Cd) is a non-essential element that is highly mobile within organisms where, following plant uptake, subcellular distribution plays an important role in plant tolerance and detoxification. Cd uptake and subcellular distribution were studied in two paddy rice varieties (Japonica and Indica) hydroponically cultivated in Cd-containing solutions. Japonica rice grains containing Cd were also collected from a Cd-contaminated site and subjected to various cooking treatments (boiled, stir-fried, steamed, and control) to determine the influence of cooking method on the subcellular distribution of Cd. Cd treatment inhibited both shoot height and root length, especially in Japonica, where for the same Cd treatment, Japonica accumulated more $\mathrm{Cd}$ in roots and shoots than Indica. Most of the accumulated Cd $(92 \%$ - 99\%) was bound to the cell wall and vacuoles, and decreased in the order: soluble fraction $\left(F_{s}\right)>$ cell wall fraction $\left(F_{c w}\right)>$ organelle fraction $\left(F_{c o}\right)$. Subcellular Cd concentrations in rice grains were significantly affected by cooking treatment. The proportion of trophically available Cd decreased with increase in cooking duration and temperature, indicating that consuming steamed and stir-fried rice had a lower Cd exposure risk than consuming boiled rice.
\end{abstract}

\section{Keywords}

Indica, Japonica, Risk Assessment, Trophically Available

\section{Introduction}

Due to the application of fertilizers, irrigation with industrial wastewater, and atmospheric deposition, agricultural soils contaminated with cadmium (Cd) are a worldwide pollution problem [1]. Cadmium is a non-essential 
element that can inhibit plant growth even at low concentrations. Cd poses potential risks to humans and ecosystem health through food chain contamination. To decrease toxicity many studies have reported that plants compartmentalize heavy metals (HMs) in the cell wall or vacuoles [2]-[5], or form complexes with low molecular weight organic compounds [6]-[8]. In most plants, transfer of Cd from roots to shoots is driven by transpiration [9], and Cd accumulation decreases in the order: roots $>$ leaves $>$ grains or seeds [10].

Rice is the most important crop in Asia, and consumption of paddy rice containing Cd is detrimental to human health [1]. The ability to take up, transport, and accumulate Cd differs amongst rice cultivars [11]. Field studies in Taiwan have shown that more Cd accumulates in the grains of Indica varieties than in Japonica [12]. Furthermore, even when the total Cd concentration in the soil was lower than the control standard for croplands (5 $\mathrm{mg} / \mathrm{kg}$ ) enacted by Taiwan's Environmental Protection Agency (EPA), more than $40 \%$ of the Indica variety accumulated more than $0.4 \mathrm{mg} / \mathrm{kg}$ (food quality standard; FQS) of Cd in the grains [12].

Elevated levels of Cd were first reported in rice in northern Taiwan in 1982 [13], and Kuo et al. [14] observed that consuming rice containing Cd affected the health of nearby residents. Many studies have reported that consuming rice products is the major Cd exposure pathway for humans [15] [16]. After harvesting, grains of rice are subjected to various cooking methods before consumption. He et al. [17], in studying fish, reported that cooking treatments affected the subcellular distribution of HMs, and thus, the trophic availability of copper and zinc. Approximately half of the arable land in Taiwan is currently used to plant paddy rice, and Japonica is the major variety (approximately 90\%) because of taste [12]. This desirability makes this variety more common than the Indica variety. Although various paddy rice varieties have been planted in different $\mathrm{Cd}$-contaminated sites to test the differences in accumulation capacity between varieties [12], knowledge of the factors governing Cd uptake and sequestration is insufficient. No studies on the effect of cooking treatments on the subcellular distribution and trophic availability of $\mathrm{Cd}$ in paddy rice grains have yet been published.

This manuscript presents the results of two studies conducted during the same period. To understand the differences in accumulation and translocation of Cd between seedlings of two paddy rice varieties, both varieties were hydroponically grown in solutions exposed to increasing Cd concentrations, and the subcellular distribution was determined. In a separate experiment, grains containing elevated levels of Cd (sampled from Cdcontaminated cropland) were cooked using three different methods commonly used to prepare rice for consumption in Taiwan (stir-fried, boiled, steamed). A control group was also created. The objectives were thus two-fold, to assess the effects of 1) Cd treatments on seedling growth and Cd accumulation in paddy rice and 2) cooking treatments on the subcellular distribution of $\mathrm{Cd}$ in the grains of paddy rice.

\section{Materials and Methods}

\subsection{Hydroponic Experiment}

A modified hydroponic experiment was conducted in accordance with previous studies [18] [19]. Seeds of two paddy rice varieties, Indica (Taichung Sen No. 10) and Japonica (Taiken No. 9), were sterilized with $2 \% \mathrm{H}_{2} \mathrm{O}_{2}$ for 10 minutes, and then rinsed with deionized water. Solutions ( $\mathrm{pH}$ 5.5) were prepared in accordance with the methods of Yoshida et al. [20] and spiked with Cd to give final concentrations of 1.0, 2.5, and 5.0 $\mu \mathrm{M}$. Ten 15day-old seedlings with similar external appearances, i.e., shoot height and root length, were planted in triplicate in solutions containing $\mathrm{Cd}$ and solutions were replaced every 2 - 3 days.

\subsection{Harvest and Subcellular Distribution Analysis}

Paddy rice was harvested after 15 days growth in accordance with He et al. [21] and divided into roots and shoots. The fresh weight, shoot height, and root length were measured and recorded immediately after the rice was harvested. The length and width of the largest expanded leaf of each seedling were also measured in triplicate and leaf area was estimated as $50 \%$ of the product of these measurements (i.e., leaf area $=$ length $\times$ width $/ 2$ ). The chlorophyll content of the largest expanded leaf of each seedling was measured with a chlorophyll meter (SPAD-502, Konica Minolta, Osaka, Japan). The fresh roots of the paddy rice were first rinsed with $0.5 \mathrm{mM}$ $\mathrm{CaCl}_{2}$ solution to remove adsorbed $\mathrm{Cd}$ and then subjected to subcellular distribution analysis in accordance with previous studies [18] [22] [23], with minor modifications. Briefly, fresh plant tissues were mixed with a buffer solution (0.4 M sucrose, $50 \mathrm{mM}$ Tris-HCl (pH 7.5), and $1.0 \mathrm{mM}$ dithioerythritol), ground with a mortar and pestle, and homogenized at $4^{\circ} \mathrm{C}$. The homogenized solution was first centrifuged at $3000 \mathrm{rpm}$ for $30 \mathrm{sec}$, and the re- 
sidue was designated as the cell wall fraction $\left(\mathrm{F}_{\mathrm{cw}}\right)$. The suspension was then centrifuged at 12,000 rpm for 30 $\min$. The residue and the suspension were designated as the organelle fraction $\left(\mathrm{F}_{\mathrm{co}}\right)$ and the soluble fraction $\left(\mathrm{F}_{\mathrm{s}}\right)$, respectively. The $\mathrm{Cd}$ concentration in $\mathrm{F}_{\mathrm{s}}$ was measured using an inductive coupled plasma optical emission spectrometer (ICP-OES; PerkinElmer Optima 2100 DV) directly, while the other two residues were oven dried to a constant weight at $60^{\circ} \mathrm{C}$, digested with $\mathrm{HNO}_{3} / \mathrm{HClO}_{4}(\mathrm{v} / \mathrm{v}=3 / 1)$, and the Cd concentration in the digestant was measured using the ICP/OES.

\subsection{Cooking Treatments}

Cooking experiments were conducted using the rice grains of Japonica variety (Taiken No. 9) obtained from cropland contaminated with $\mathrm{Cd}$ in central Taiwan. Rice grains of Indica variety with Cd concentration higher than the Taiwanese FQS $(0.4 \mathrm{mg} / \mathrm{kg}$ ) were not available and thus not conducted. The mean Cd concentration of the raw rice was $0.42 \mathrm{mg} / \mathrm{kg}$, which was higher than the Taiwanese FQS. Rice samples were rinsed with tap water, and then deionized water to remove attached dusts. Four cooking treatments, including untreated (control), boiled, steamed, and stir-fried after being boiled were used to test the effects of cooking on subcellular distribution of $\mathrm{Cd}$ in rice grains. The cooking duration and temperature were 40 minutes and $120^{\circ} \mathrm{C}$ for the boiled treatment, 60 minutes and $140^{\circ} \mathrm{C}$ for the steamed treatment, and 5 minutes and $240^{\circ} \mathrm{C}$ for the stir-fried treatment (after boiling), respectively. Each treatment was triplicated and the subcellular distribution of $\mathrm{Cd}$ in each cooked rice sample was analyzed according to the method described in Section 2.2.

\subsection{Quality Control and Statistical Analysis}

The concentrations of the three $\mathrm{Cd}$ fractions were totaled, and the recovery determined as the ratio between $\mathrm{F}_{\mathrm{cw}}+\mathrm{F}_{\mathrm{co}}+\mathrm{F}_{\mathrm{s}}$ and the total Cd concentration. Data were considered valid when the recovery was between $90 \%$ $110 \%$. Statistical analysis was performed using SPSS (Statistical Package for Social Science, Armonk, NY, USA). The differences in the shoot height, root length, soil-plant analysis development (SPAD) readings, Cd accumulation, subcellular distribution, and transfer factor among the mean values of the $\mathrm{Cd}$ treatments and the varieties were evaluated with one-way analysis of variance (ANOVA), followed by the least significant difference (LSD) test with a statistical significance of $p=0.05$.

\section{Results}

\subsection{Paddy Rice Growth}

No visible symptoms of Cd toxicity (i.e., chlorosis or wilting) were observed during the experiment. Shoot height and root length of the two paddy rice varieties varied with treatment (Figure 1). The Japonica variety had significantly longer shoots compared with Indica $(p<0.05)$, while Cd treatment had no significant influence on shoot height. Compared to the $1.0 \mu \mathrm{M}$ Cd treatment the Japonica variety grown in the 2.5 and $5.0 \mu \mathrm{M}$ Cd concentrations had significantly shorter roots $(p<0.05)$. However, this same phenomenon was not observed in the Indica variety. The root length of the Indica seedlings grown in $2.5 \mu \mathrm{M} \mathrm{Cd}$ increased significantly (88\%) relative to the $1.0 \mu \mathrm{M}$ Cd concentration $(p<0.05)$. Cd treatments had no significant effect on SPAD readings of Indica leaves (Figure 2). Compared to the Indica variety, the Japonica samples had higher or significantly higher SPAD $(p<0.05)$. Treatment with $2.5 \mu \mathrm{M}$ Cd increased and significantly increased $(p<0.05)$ the SPAD readings of the Japonica variety, compared with the 1.0 and $5.0 \mu \mathrm{M}$ Cd concentrations, respectively.

\subsection{Cd Accumulation}

Most Cd accumulated in the roots of both rice varieties (Figure 3). For the same Cd treatment and compared to the Indica variety, the roots and shoots of the Japonica had significantly $(p<0.05)$ higher Cd concentrations. The accumulating capacity of the plants was in the decreasing order of root $>$ leaf $>$ cereal/grain. There were no significant differences between Cd treatments in terms of the Cd concentration in the roots and shoots of the Indica variety. Although the Cd treatments significantly affected the Cd accumulation in the Japonica variety, the trend was not identical. In the samples treated with the $2.5 \mu \mathrm{M} \mathrm{Cd}$, the roots and shoots of the Japonica variety had significantly higher Cd concentrations compared with the two other treatments $(p<0.05)$. 


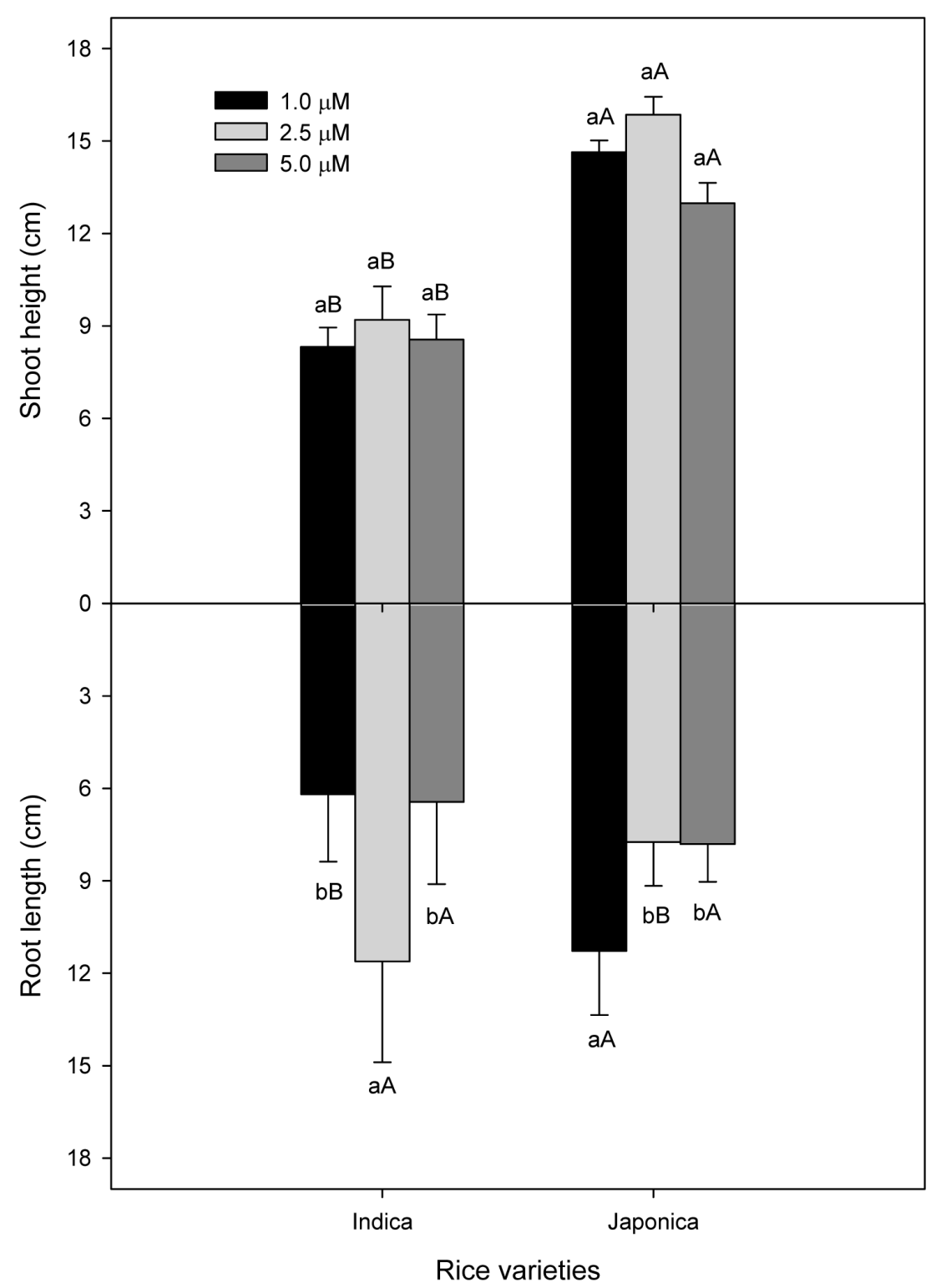

Figure 1. Effects of Cd treatment on shoot height and root length of two paddy rice varieties. Treatments with the same lowercase letters indicate no significant difference between Cd treatments for the same variety. Treatments with the same capital letters indicate no significant difference between the varieties for the same Cd treatment. Replicates (n) $=3$.

\subsection{Subcellular Distribution of Cd in the Seedlings}

Subcellular distribution of $\mathrm{Cd}$ in the two rice varieties varied with $\mathrm{Cd}$ treatment (Figure 4 and Figure 5). Between $92 \%$ - 99\% of the Cd was compartmentalized in the $\mathrm{F}_{\mathrm{cw}}$ and $\mathrm{F}_{\mathrm{s}}$ fractions. For both rice varieties $\mathrm{Cd}$ was primarily compartmentalized in $\mathrm{F}_{\mathrm{s}}$, which accounted for $54 \%$ - 66\% of the total accumulated Cd (Figure 4 and Figure 5). For the roots and shoots of the Indica variety, $37 \%-43 \%$ and $30 \%-43 \%$ of the Cd was in $\mathrm{F}_{\mathrm{cw}}$, respectively. Similarly, more than $64 \%$ of $\mathrm{Cd}$ in the tissues of the Japonica samples was compartmentalized in $\mathrm{F}_{\mathrm{s}}$ and $17 \%-32 \%$ was in $\mathrm{F}_{\mathrm{cw}}$ (Figure 5).

\subsection{Translocation Factor}

The transfer factor (TF) or ratio of the shoot HM concentration to the root HM concentration, is commonly 


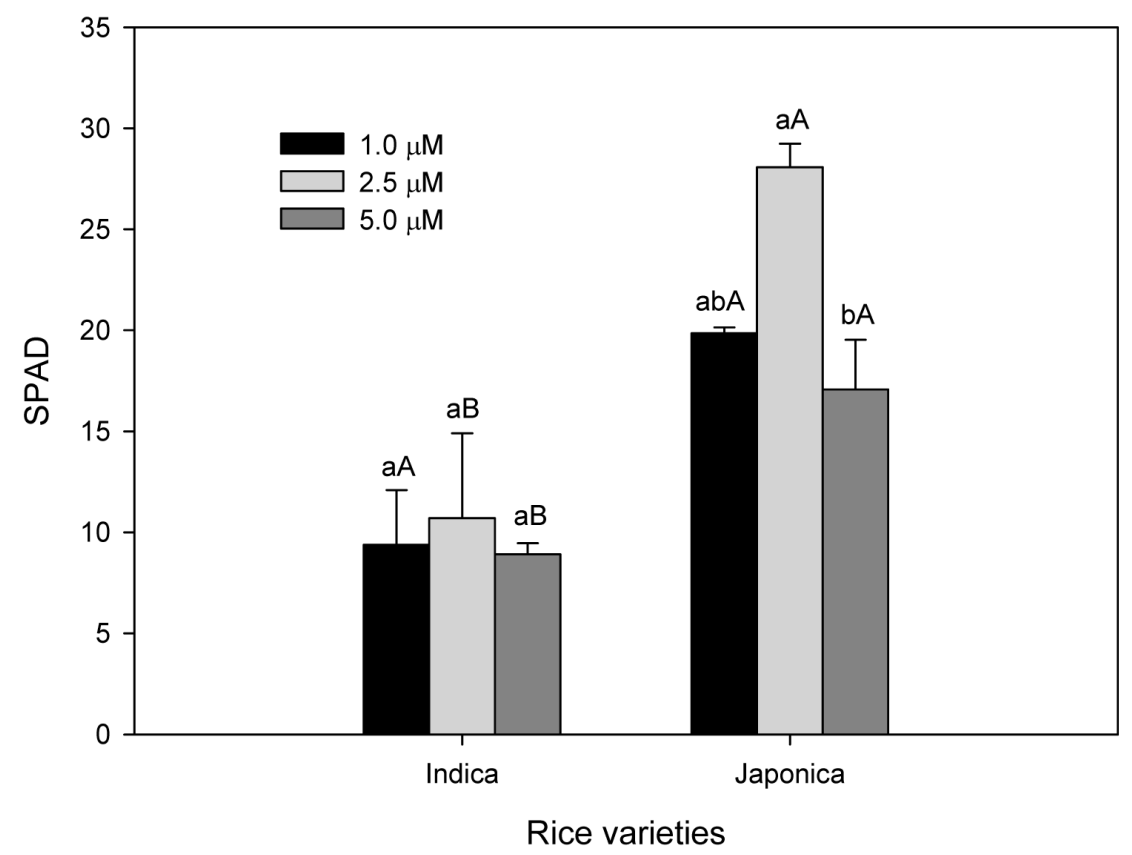

Figure 2. Effects of Cd treatment and variety on SPAD readings of two paddy rice varieties. Treatments with the same lowercase letters indicate no significant difference between $\mathrm{Cd}$ treatments for the same variety. Treatments with the same capital letters indicate no significant difference between the varieties for the same Cd treatment. Replicates $(n)=3$.

used to identify HM translocation in plants [24]. Even though more, or significantly more, $(p<0.05)$ Cd accumulated in the shoots and roots of the Japonica variety than in the Indica variety (Figure 3), variety did not significantly affect the TF, except for the $5.0 \mu \mathrm{M}$ Cd concentration (Figure 6).

\subsection{Effect of Cooking Treatments on the Subcellular Distribution of Cd in the Grains}

The proportion of $\mathrm{Cd}_{\text {in }} \mathrm{F}_{\mathrm{cw}}, \mathrm{F}_{\mathrm{co}}$, and $\mathrm{F}_{\mathrm{s}}$ in untreated rice (control) was $69.6 \% \pm 25.9 \%, 7.9 \% \pm 13.7 \%$, and $22.5 \% \pm 15.7 \%$, respectively (Figure 7). For the boiled treatment, the proportion of $\mathrm{F}_{\mathrm{cw}}$ decreased slightly $(53.5 \% \pm 34.7 \%)$, whereas the proportion of $\mathrm{F}_{\mathrm{co}}(12.0 \% \pm 7.9 \%)$ and $\mathrm{F}_{\mathrm{s}}(34.6 \% \pm 27.8 \%)$ increased slightly compared to the control. However, these differences were not statistically significant. In contrast, the steamed treatment had significantly increased proportion of $\mathrm{Cd}$ in $\mathrm{F}_{\mathrm{cw}}(79.8 \% \pm 10.2 \%)$ and decreased proportion of $\mathrm{Cd}$ in $\mathrm{F}_{\mathrm{s}}(11.2 \% \pm 6.9 \%)$. No significant difference between the steamed treatment $(9.0 \% \pm 5.3 \%)$ and the control was observed for $\mathrm{F}_{\mathrm{co}}$. For the stir-fried treatment, the proportion of $\mathrm{Cd}$ in $\mathrm{F}_{\mathrm{cw}}$ was as high as $96.2 \% \pm 0.5 \%$ and the proportion of $\mathrm{Cd}$ in $\mathrm{F}_{\mathrm{co}}$ and $\mathrm{F}_{\mathrm{s}}$ was only $1.9 \% \pm 0.5 \%$ and $1.8 \% \pm 0.1 \%$, respectively.

\section{Discussion}

Many researchers use root length as a useful index of plant stress [1] [25] and Cd does affect the root length of wheat [26]. This study showed that the Indica variety of rice was not as sensitive to Cd as the Japonica variety (Figure 1). The SPAD meter is an effective tool for non-destructive estimation of the total chlorophyll concentration across a range of plant ages, growing conditions, and genotypes [27]. There is a close relationship between SPAD readings and chlorophyll content, and the SPAD meter has been used to determine the chlorophyll content of leaves and to estimate the nitrogen status of rice [28] [29]. Fresh plant leaves were sampled and the subcellular distribution of $\mathrm{Cd}$ was sequentially analyzed. The chlorophyll content was thus determined with a SPAD meter in place of chemical determination because of deficiency of plant tissues. However, Hussain et al. [30] observed that the soil type, crop variety, growth stage, and leaf position affect the effectiveness of the SPAD meter. Although Shi and Cai [31] indicated that Cd has a negative effect on the chlorophyll content, we observed no negative influence in this study which may be attributed to the short-term growths. 


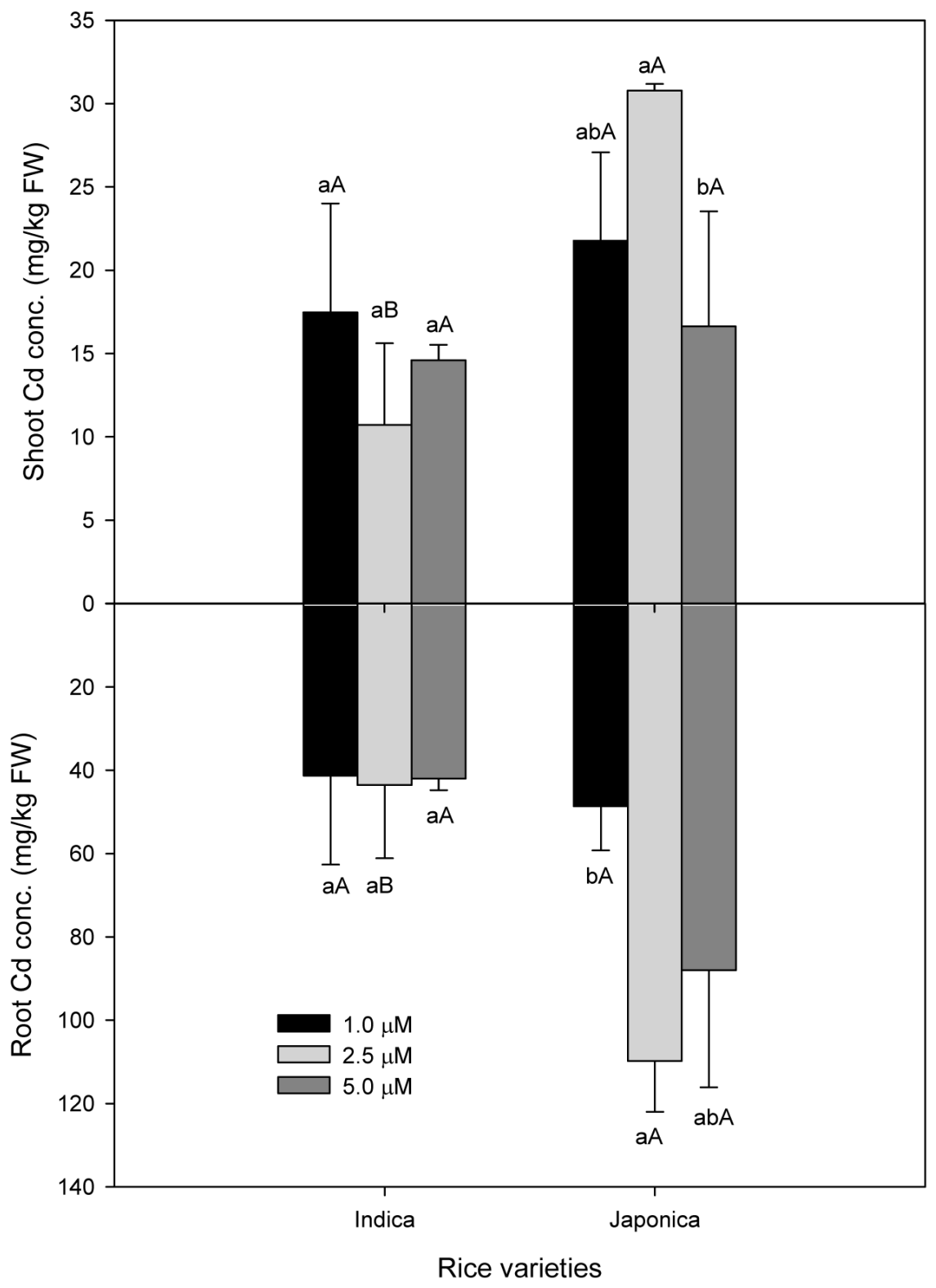

Figure 3. Effects of Cd treatment and variety on the Cd concentrations in the shoots and roots of two paddy rice varieties. Treatments with the same lowercase letters indicate no significant difference between the Cd treatments for the same variety. Treatments with the same capital letters indicate no significant difference between the varieties for the same Cd treatment. Replicates $(\mathrm{n})=3$.

Irrespective of the paddy rice variety and in agreement with He et al. [21] and Zhang et al. [18], the roots of paddy rice accumulated more $\mathrm{Cd}$ than the shoots (Figure 3). The uneven Cd distribution among the plant organs seems to be an important strategy in response to Cd stress and protects plants from Cd toxicity. Compared to the field study conducted by Römkens et al. [32] in $19 \mathrm{Cd}$-contaminated paddy fields with total Cd concentrations ranging from $<0.1$ to almost $30 \mathrm{mg} / \mathrm{kg}$, the Cd concentration in the roots of the two paddy rice varieties studied was 1.3 to 3.6 times higher because of the high availability of $\mathrm{Cd}$ in the hydroponic experiment relative to the soil environment.

For the same hydroponic Cd concentration the Japonica variety had higher or significantly higher $(p<0.05)$ $\mathrm{Cd}$ concentrations in the roots and shoots compared with the Indica variety. This was not in agreement with the 


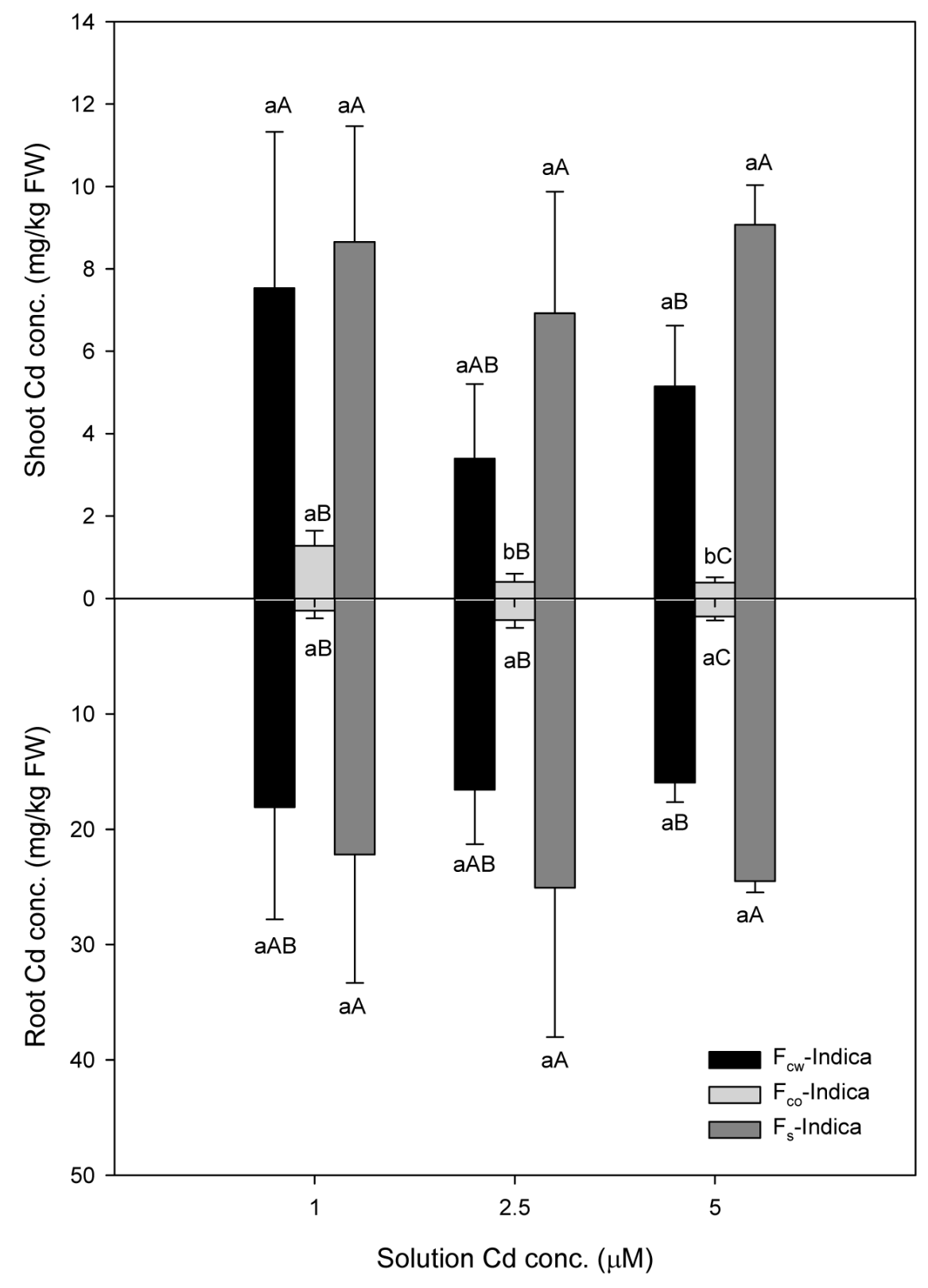

Figure 4. Effects of $\mathrm{Cd}$ treatment on the subcellular distribution $\left(\mathrm{F}_{\mathrm{cw}}\right.$ : Cell wall fraction, $\mathrm{F}_{\mathrm{co}}$ : Organelle fraction, $\mathrm{F}_{\mathrm{s}}$ : Soluble fraction) of $\mathrm{Cd}$ in the shoots and roots of the Indica variety. Treatments with the same lowercase letters indicate no significant difference between the Cd concentrations for the same Cd fraction. Treatments with the same capital letters indicate no significant difference between the Cd fractions for the same Cd concentration. Replicates (n) $=3$.

observations of many researchers that have shown a 1.5 to 3.0 times higher Cd concentration accumulating in the grains of the Indica variety compared with the Japonica variety [32] [33], which is related to the oxidizing and translocation capacity of the roots [12] [34]. Although more Cd accumulated in the roots and shoots of the Japonica variety, the accumulated Cd would not be easily transferred to the grains.

Many studies have shown that plants compartmentalize HMs in the cell wall to alleviate toxicity [3] [35]-[37] where the proteins and polysaccharides of the cell wall form complexes with HMs and restrict their translocation [38]. The results observed in this study (Figure 4 and Figure 5) support this hypothesis. The plant cell wall is primarily composed of cellulose, hemicellulose, lignin, and mucilage, as well as proteins, which contain many 


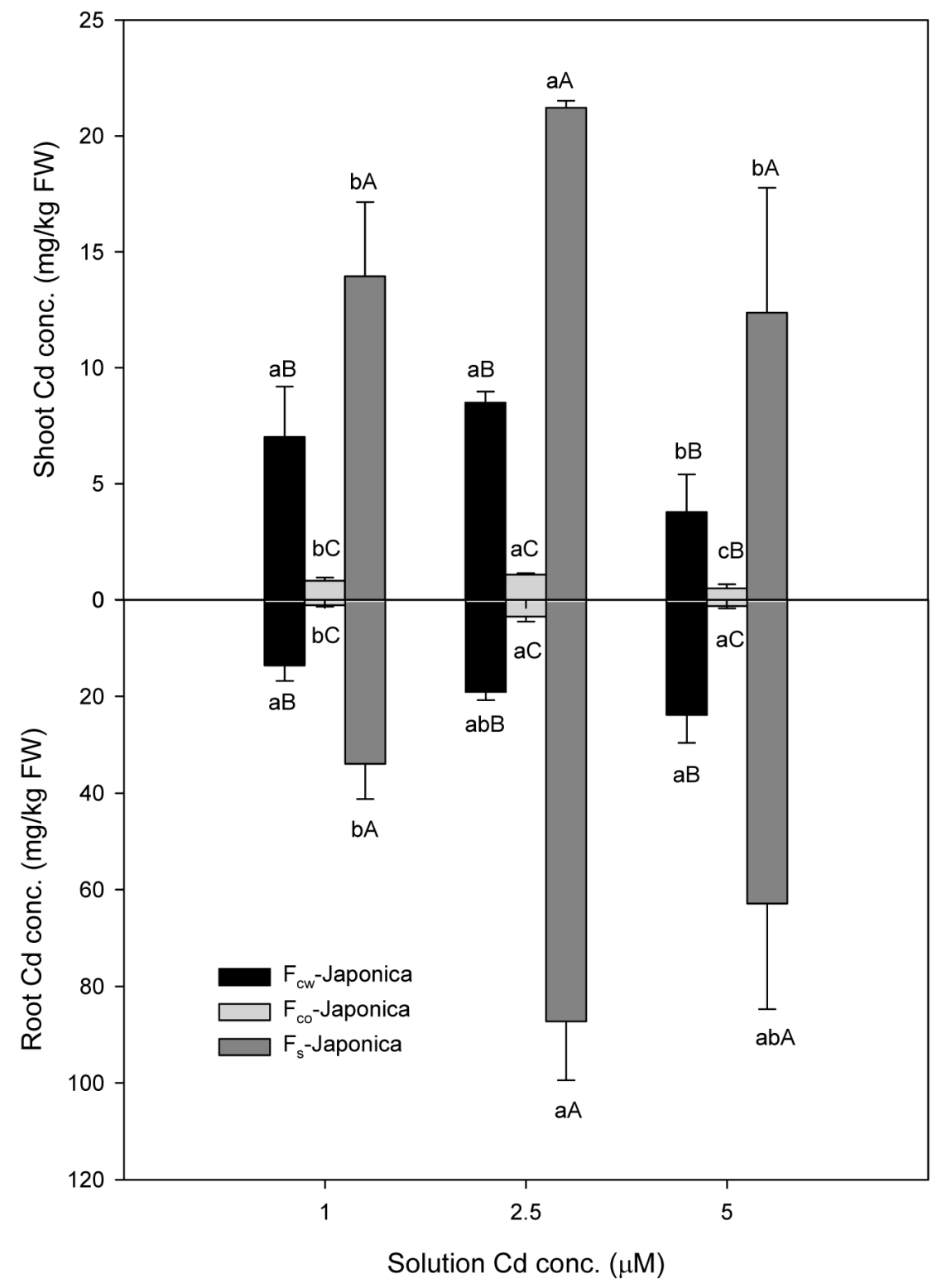

Figure 5. Effects of $\mathrm{Cd}$ treatment on the subcellular distribution $\left(\mathrm{F}_{\mathrm{cw}}\right.$ : Cell wall fraction, $\mathrm{F}_{\mathrm{co}}$ : Organelle fraction, $\mathrm{F}_{\mathrm{s}}$ : Soluble fraction) of $\mathrm{Cd}$ in the shoots and roots of the Japonica variety. Treatments with the same lowercase letters indicate no significant difference between the Cd concentrations for the same Cd fraction. Treatments with the same capital letters indicate no significant difference between the $\mathrm{Cd}$ fractions for the same Cd concentration. Replicates $(n)=3$.

functional groups that could form complexes with $\mathrm{Cd}$ and restrict translocation, thus further protecting the organelles from Cd toxicity [39]. Although the complexes were not determined in this study, the importance of cell walls and their sub-fractions in the adsorption of Cd by willow roots was proven by Chen et al. [40].

He et al. [21] planted two rice varieties in a solution that contained $0.5 \mathrm{mM} \mathrm{Cd}$ and found that the subcellular distribution decreased in the following order: $\mathrm{F}_{\mathrm{cw}}>\mathrm{F}_{\mathrm{s}}>\mathrm{F}_{\mathrm{co}}$. In agreement with Zhu et al. [41], the proportion of $\mathrm{Cd}$ in $\mathrm{F}_{\mathrm{s}}$ increased as the Cd levels in the solution increased. As observed by Su et al. [42], there was a negative relationship between the proportion of root $\mathrm{Cd}$ in $\mathrm{F}_{\mathrm{s}}$ and that in $\mathrm{F}_{\mathrm{cw}}\left(\mathrm{F}_{\mathrm{cw}}=94.43-0.96 \mathrm{~F}_{\mathrm{s}} ; \mathrm{r}^{2}=0.99\right)$. The negative charge of the cell wall is the first barrier restricting Cd entrance into cells [43]. Compared with the Japonica variety, the Cd concentrations in the roots of Indica were approximately $16 \%-21 \%$ higher in $\mathrm{F}_{\mathrm{cw}}$ and $16 \%$ - 


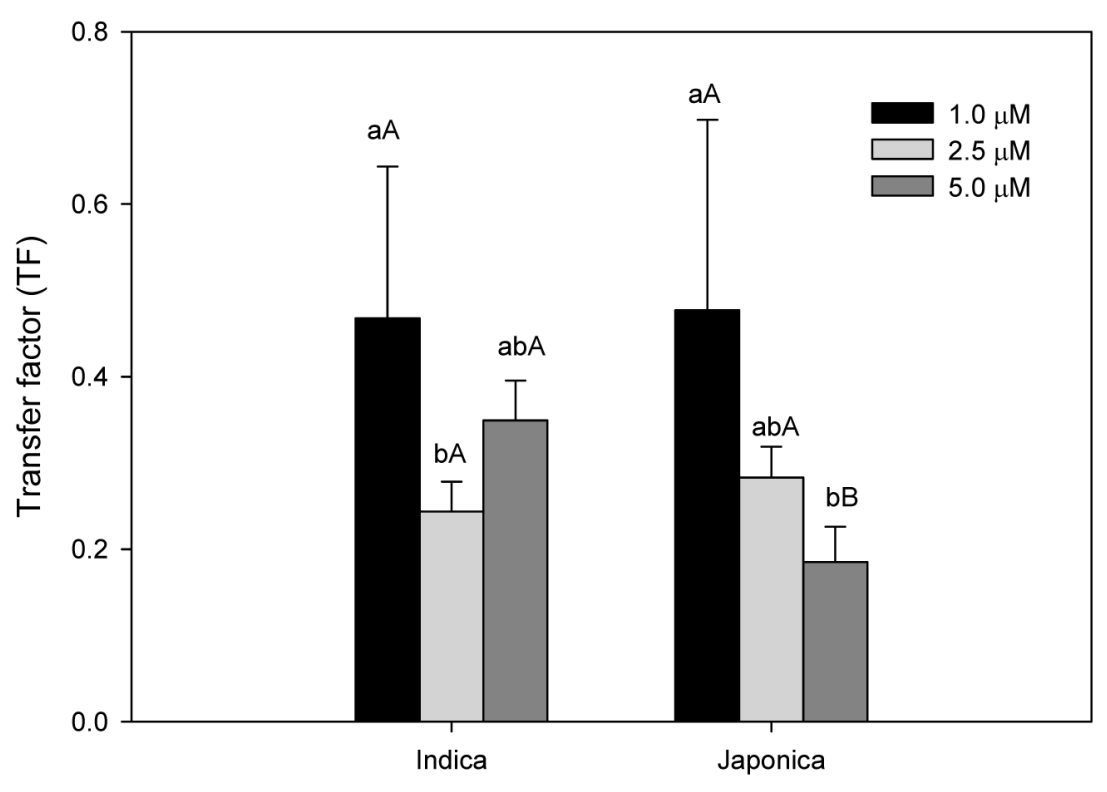

Rice species

Figure 6. Effects of Cd treatment and variety on the translocation factor of two paddy rice varieties. Treatments with the same lowercase letters indicate no significant difference between the Cd treatments for the same variety. Treatments with the same capital letters indicate no significant difference between the varieties for the same Cd treatment. Replicates $(\mathrm{n})=3$.

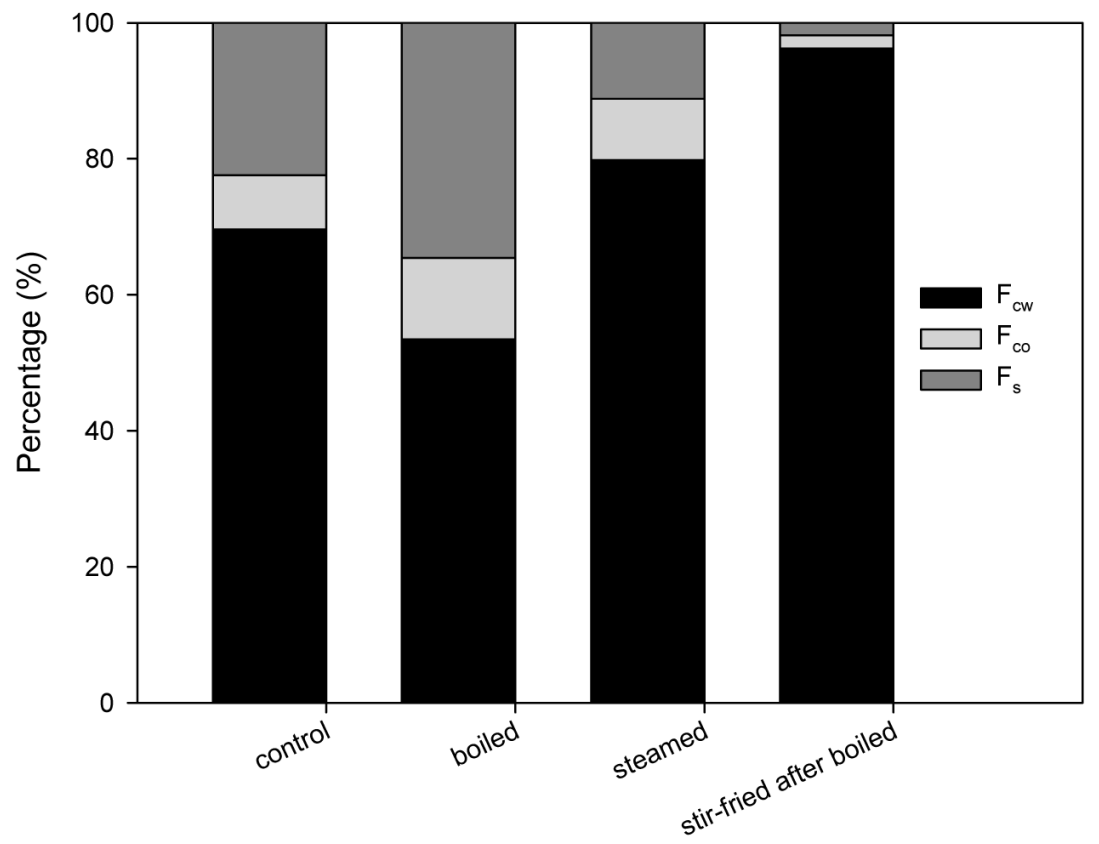

Cooking treatments

Figure 7. Effects of different cooking treatments on the subcellular distribution of Cd in the grains of Japonica grown on Cd-contaminated soil. Replicates (n) $=3$.

21\% lower in $\mathrm{F}_{\mathrm{s}}$ (Figure 4 and Figure 5), suggesting that the cell walls of Indica roots restricted Cd more than Japonica roots. This was in agreement with the results presented in Figure 3, which show that significantly less 
Cd was translocated to the shoots of the Indica variety. In agreement with Weigel and Jäger [22], for Japonica roots $70 \%-80 \%$ of the Cd was compartmentalized in $\mathrm{F}_{\mathrm{s}}$ (Figure 5), which showed that most of the Cd in Japonica roots had high mobility. This phenomenon is clearly observed in the $2.5 \mu \mathrm{M}$ treatment where levels of Cd in $\mathrm{F}_{\mathrm{s}}$ result in higher levels of $\mathrm{Cd}$ accumulation in shoots (Figure 3).

The hydroponic study showed that the TF of the two paddy rice varieties ranged between 0.18 and 0.48 and only the Indica variety had a significantly higher TF in the $5.0 \mu \mathrm{M}$ Cd treatment (Figure 6). In a previous study, two rice cultivars differing in Cd tolerance and grown hydroponically in Cd solutions with Cd concentrations similar to those used in this study [44] exhibited much lower TFs between 0.09 and 0.13 . This phenomenon is in agreement with subcellular distribution results described in Section 3.3 because Cd was compartmentalized in the $F_{s}$ for the roots of the two rice varieties (Figure 4 and Figure 5). In contrast, the major portion of Cd absorbed by the roots of the four rice plants was localized in the cell wall [18] [21]. The transfer of Cd from roots to shoots differs between rice varieties and cultivars. The transfer ability of the Indica and Japonica varieties is different, and the Cd concentrations in the Indica variety grown in Cd-contaminated paddy fields are 2 to 3 times higher than in the Japonica variety [12]. However, significantly more $(p<0.05)$ Cd accumulated in the roots and shoots of the Japonica variety (Figure 3). Römkens et al. [32] showed that the TF of Cd for Indica and Japonica when grown in soil was $0.061-0.096$ and $0.025-0.037$, respectively, suggesting that the Japonica variety was suitable for planting in Cd-contaminated fields. Although different media were used, making a direct comparison with this study is difficult because the transfer capacity of Cd to grain seemed far smaller than that of shoot.

Salt et al. [9] reported that the translocation of Cd in plants was driven by transpiration. Many studies have reported that Cd has a negative effect on the leaf area, chlorophyll content [30] [44], lamina and mesophyll thickness, and epidermal cell size [45]. Transpiration plays an important role in the mass flow, and thus Cd translocation to the shoots of Brassica juncea [9] and Impatiens walleriana [46]. Liu et al. [47] observed that there was a significantly positive relationship between shoot $\mathrm{Cd}$ concentration and leaf transpiration. Inhibiting leaf transpiration decreases the translocation of Cd from rice roots to shoots [48]. The estimated leaf area (LA), the product of leaf length and weight, had a positive linear relationship with $\mathrm{Cd}$ concentrations in roots $\left(\mathrm{Cd}_{\text {root }}\right)$ and shoots $\left(\mathrm{Cd}_{\text {shoot }}\right)$ of the two rice varieties (Equation (1) and Equation(2)), which indirectly revealed a transpiration effect on $\mathrm{Cd}$ accumulation.

$$
\begin{aligned}
& \mathrm{Cd}_{\text {root }}=44.27 \times \mathrm{LA}-50.85\left(\mathrm{r}^{2}=0.73\right) \\
& \mathrm{Cd}_{\text {shoot }}=11.14 \times \mathrm{LA}-9.78\left(\mathrm{r}^{2}=0.83\right)
\end{aligned}
$$

The subcellular portions of $\mathrm{Cd}$ in the rice were significantly affected by cooking treatments. Generally, the amount of Cd concentration in $\mathrm{F}_{\mathrm{cw}}$ increased as cooking duration and temperature increased. Traditionally, the health risk of Cd through rice consumption was based solely on total Cd concentration. However, not all Cd in a plant is available and the proportion of $\mathrm{HMs}$ in $\mathrm{F}_{\mathrm{co}}$ and $\mathrm{F}_{\mathrm{s}}$ are considered trophically available, whereas the proportion in $\mathrm{F}_{\mathrm{cw}}$ is not [49]-[51]. Using this concept of trophically available metal (TAM), even though a real assessment of trophic exposure was not conducted in this study, the health risk of Cd due to rice consumption may be decreased after all cooking treatments. Since the proportion of trophically available Cd decreased as both cooking duration and temperature increased, this suggests that consuming steamed and stir-fried rice has a lower risk of exposure to $\mathrm{Cd}$ than consuming boiled rice. Although the food value and quality of rice may change with cooking treatment, this is also useful in decreasing the proportion of trophically available Cd. Recently, He et al. [17] studied the correlation between the bioaccessibility and subcellular fractionation of HMs in marine fish, and suggested that the subcellular distribution of HMs should be considered as a better assessment of the human health risk associated with seafood consumption. In the present study, subcellular distributions of Cd in rice varied with cooking treatment, which enabled assessment of trophic transfer of $\mathrm{Cd}$ in the terrestrial food chain and subsequently for human health risk assessments. However, it is a big step to go from elevated Cd levels in rice grains to human health risk assessment. We have to emphasize that greater Cd exposure is an indicator of potential increased risk, but it is not a risk itself. Real risk estimation requires extensive epidemiology studies or animal feeding trials, none of which are conducted here.

\section{Conclusion}

Paddy rice varieties grown hydroponically in Cd solutions showed significant differences in Cd accumulation, 
translocation, and compartmentalization. Among the three subcellular fractions analyzed in this study, the cell wall played the most important role in the detoxification of $\mathrm{Cd}$. The soluble fraction of $\mathrm{Cd}$ in the roots had high mobility. Different cooking treatments affected the subcellular distribution of $\mathrm{Cd}$ in grains, and thus trophic availability. But to extend this approach to reduce human health risk without any actual experience is a big step.

\section{Acknowledgements}

The authors would like to thank the Ministry of Science and Technology (previous National Science Council) of the Republic of China for financially supporting this research under Contract No. NSC 101-2621-M-451-001 and NSC 101-2621-M-451-002. We also thank the students of Soil Survey and Environmental Analysis Laboratory, Department of Post-Modern Agriculture, MingDao University, for their assistance during pot experiment and experimental analysis.

\section{References}

[1] Liu, X.Q., Peng, K.J., Wang, A.G., Lian, C.L. and Shen, Z.G. (2010) Cadmium Accumulation and Distribution in Population of Phytolacca americana L. and the Role of Transpiration. Chemosphere, 78, 1136-1141. http://dx.doi.org/10.1016/j.chemosphere.2009.12.030

[2] Lasat, M.M., Baker, A.J.M. and Kochian, L.V. (1996) Physiological Characterization of Root $\mathrm{Zn}^{2+} \mathrm{Absorption}^{2}$ and Translocation to Shoots in Zn Hyperaccumulator and Nonaccumulator Species of Thlaspi. Plant Physiology, 112, $1715-1722$.

[3] Küpper, H., Zhao, F.J. and McGrath, S.P. (1999) Cellular Compartmentation of Zinc in Leaves of the Hyperaccumulator Thlaspi caerulescens. Plant Physiology, 119, 305-311. http://dx.doi.org/10.1104/pp.119.1.305

[4] Jarvis, M.D. and Leung, D.W.M. (2002) Chelated Lead Transport in Pinus radiate: An Ultrastructural Study. Environmental and Experimental Botany, 48, 21-32. http://dx.doi.org/10.1016/S0098-8472(02)00005-9

[5] Lugon-Moulin, N., Zhang, M., Gadani, F., Rossi, L., Krauss, D. and Wanger, G.J. (2004) Critical Review of the Science and Options for Reducing Cadmium in Tobacco (Nicotiana tabacum L.) and Other Plants. Advances in Agronomy, 83, 111-180. http://dx.doi.org/10.1016/S0065-2113(04)83003-7

[6] Salt, D.E., Prince, R.C., Baker, A.J.M., Raskin, I. and Pickering, I.J. (1996) Zinc Ligands in the Metal Hyperaccumulator Thlaspi caerulescens as Determined Using X-Ray Adsorption Spectroscopy. Environmental Science \& Technology, 33, 713-717. http://dx.doi.org/10.1021/es980825x

[7] Wójcik, M., Vangronsveld, J. and Tukiendorf, A. (2005) Cadmium Tolerance in Thlaspi caerulescens I. Growth Parameters. Metal Accumulation and Phytochelatin Synthesis in Response to Cadmium. Environmental and Experimental Botany, 53, 151-161. http://dx.doi.org/10.1016/S0098-8472(04)00046-2

[8] Han, F., Shan, X., Zhang, S., Wen, B. and Owens, G. (2006) Enhanced Cadmium Accumulation in Maize Roots-The Impact of Organic Acids. Plant and Soil, 289, 355-368. http://dx.doi.org/10.1007/s11104-006-9145-9

[9] Salt, D.E., Prince, R.C., Pickering, I.J. and Raskin, I. (1995) Mechanisms of Cadmium Mobility and Accumulation in Indian Mustard. Plant Physiology, 109, 1427-1433.

[10] Wagner, G.J. (1993) Accumulation of Cadmium in Crop Plants and Its Consequences to Human Health. Advances in Agronomy, 51, 173-212. http://dx.doi.org/10.1016/S0065-2113(08)60593-3

[11] Yang, X., Baligar, V.C., Martens, D.C. and Clark, R.B. (1995) Influx, Transport and Accumulation of Cadmium in Plant Species Grown at Different $\mathrm{Cd}^{2+}$ Activities. Journal of Environmental Science and Health, 30, 569-583. http://dx.doi.org/10.1080/03601239509372954

[12] Hseu, Z.Y., Su, S.W., Lai, H.Y., Guo, H.Y., Chen, T.C. and Chen, Z.S. (2010) Remediation Techniques and Heavy Metal Uptake by Different Rice Varieties in Metal-Contaminated Soils of Taiwan: New Aspects for Food Safety Regulation and Sustainable Agriculture. Soil Science \& Plant Nutrition, 56, 31-52. http://dx.doi.org/10.1111/j.1747-0765.2009.00442.x

[13] Chen, C.M. and Liu, M.C. (2006) Ecological Risk Assessment on a Cadmium Contaminated Soil Landfill-A Preliminary Evaluation Based on Toxicity Tests on Local Species and Site-Specific Information. Science of the Total Environment, 359, 120-129. http://dx.doi.org/10.1016/j.scitotenv.2005.04.041

[14] Kuo, S., Lai, M.S. and Lin, C.W. (2006) Influence of Solution Acidity and $\mathrm{CaCl}_{2}$ Concentration on the Removal of Heavy Metals from Metal-Contaminated Rice Soils. Environmental Pollution, 144, 918-925. http://dx.doi.org/10.1016/j.envpol.2006.02.001

[15] Millis, P.R., Ramsey, M.H. and John, E.A. (2004) Heterogeneity of Cadmium Concentration in Soil as a Source of Uncertainty in Plant Uptake and Its Implications for Human Health Risk Assessment. Science of the Total Environment, 
326, 49-53. http://dx.doi.org/10.1016/j.scitotenv.2003.12.009

[16] Ikeda, M., Shimbo, S., Watanabe, T. and Yamagami, T. (2006) Correlation among Cadmium Levels in River Sediment, in Rice, in Daily Foods and in Urine of Residents in 11 Prefectures in Japan. International Archives of Occupational and Environmental Health, 79, 365-370. http://dx.doi.org/10.1007/s00420-005-0069-0

[17] He, M., Ke, C.H. and Wang, W.X. (2010) Effects of Cooking and Subcellular Distribution on the Bioaccessibility of Trace Elements in Two Marine Fish Species. Journal of Agricultural and Food Chemistry, 58, 3517-3523. http://dx.doi.org/10.1021/jf100227n

[18] Zhang, J., Sun, W.C., Li, Z.J., Liang, Y.C. and Song, A. (2009) Cadmium Fate and Tolerance in Rice Cultivars. Agronomy for Sustainable Development, 29, 483-490. http://dx.doi.org/10.1051/agro/2009008

[19] Zeng, F., Zhou, W.H., Qiu, B.I., Ali, S.F., Wu, F.B. and Zhang, G.P. (2011) Subcellular Distribution and Chemical Forms of Chromium in Rice Plants Suffering from Different Levels of Chromium Toxicity. Journal of Plant Nutrition and Soil Science, 174, 249-256. http://dx.doi.org/10.1002/jpln.200900309

[20] Yoshid, S., Forna, D.A., Cock, J.H. and Gomez, K.A. (1976) Laboratory Manual for Physiological Studies of Rice. International Rice Research Institute, Los Banos, Philippines, 62-63.

[21] He, J.Y., Zhu, C., Ren, Y.F., Yan, Y.P., Cheng, C., Jiang, D.A. and Sun, Z.X. (2008) Uptake, Subcellular Distribution, and Chemical Forms of Cadmium in Wild-Type and Mutant Rice. Pedosphere, 18, 371-377. http://dx.doi.org/10.1016/S1002-0160(08)60027-2

[22] Weigel, H.J. and Jäger, H.J. (1980) Subcellular Distribution and Chemical Form of Cadmium in Bean Plants. Plant Physiology, 65, 480-482. http://dx.doi.org/10.1104/pp.65.3.480

[23] Wallace, W.G., Lee, B.G. and Luoma, S.N. (2003) Subcellular Compartmentalization of Cd and Zn in Two Bivalves. I. Significance of Metal-Sensitive Fractions (MSF) and Biologically Detoxified Metal (BDM). Marine Ecology Progress Series, 249, 183-197. http://dx.doi.org/10.3354/meps249183

[24] Sun, Y.B., Zhou, Q.X., Wang, L. and Liu, W.T. (2009) Cadmium Tolerance and Accumulation Characteristics of Bidens pilosa L. as a Potential Cd-Hyperaccumulator. Journal of Hazardous Materials, 161, 808-814. http://dx.doi.org/10.1016/j.jhazmat.2008.04.030

[25] Juang, K.W., Lee, Y.I., Lai, H.Y., Wang, C.H. and Chen, B.C. (2012) Copper Accumulation, Translocation, and Toxic Effects in Grapevine Cuttings. Environmental Science and Pollution Research, 19, 1315-1322. http://dx.doi.org/10.1007/s11356-011-0657-3

[26] Li, D.D., Zhou, D.M., Wang, P. and Li, L.Z. (2011) Temperature Affects Cadmium-Induced Phytotoxicity Involved in Subcellular Cadmium Distribution and Oxidative Stress in Wheat Roots. Ecotoxicology and Environmental Safety, 74, 2029-2035. http://dx.doi.org/10.1016/j.ecoenv.2011.06.004

[27] Hawkins, T.S., Gardiner, E.S. and Comer, G.S. (2009) Modeling the Relationship between Extractable Chlorophyll and SPAD-502 Readings for Endangered Plant Species Research. Journal for Nature Conservation, 17, 123-127. http://dx.doi.org/10.1016/j.jnc.2008.12.007

[28] Huang, J.L., He, F., Cui, K.H., Buresh, R.J., Xu, B., Gong, W.H. and Peng, S.B. (2008) Determination of Optimal Nitrogen Rate for Rice Varieties Using a Chlorophyll Meter. Field Crops Research, 105, 70-80. http://dx.doi.org/10.1016/j.fcr.2007.07.006

[29] Lin, F.F., Qiu, L.F., Deng, J.S., Shi, Y.Y., Chen, L.S. and Wang, K. (2010) Investigation of SPAD Meter-Based Indices for Estimating Rice Nitrogen Status. Computers and Electronics in Agriculture, 71, S60-S65. http://dx.doi.org/10.1016/j.compag.2009.09.006

[30] Hussain, F., Bronson, K.F., Yadvinder, S., Bijay, S. and Peng, S. (2000) Use of Chlorophyll Meter Sufficiency Indices for Nitrogen Management of Irrigated Rice in Asia. Agronomy Journal, 92, 875-879.

[31] Shi, G.G. and Ca, Q.S. (2009) Leaf Plasticity in Peanut (Arachis hypogaea L.) in Response to Heavy Metal Stress. Environmental and Experimental Botany, 67, 112-117. http://dx.doi.org/10.1016/j.envexpbot.2009.02.009

[32] Römkens, P.F.A.M., Guo, H.Y., Chu, C.L., Liu, T.S., Chiang, C.F. and Koopmans, G.F. (2009) Prediction of Cadmium Uptake by Brown Rice and Derivation of Soil-Plant Transfer Models to Improve Soil Protection Guidelines. Environmental Pollution, 157, 2435-2444. http://dx.doi.org/10.1016/j.envpol.2009.03.009

[33] He, J.Y., Zhu, C., Ren, Y.F., Yan, Y.P. and Jiang, D.A. (2006) Genotypic Variation in Grain Cadmium Concentration of Lowland Rice. Journal of Plant Nutrition and Soil Science, 169, 711-716. http://dx.doi.org/10.1002/jpln.200525101

[34] Liu, X., Zhang, S., Shan, X.Q. and Christie, P. (2007) Combined Toxicity of Cadmium and Arsenate to Wheat and Plant Uptake and Antioxidative Enzyme Responses to Cadmium and Arsenate Co-Contamination. Ecotoxicology and Environmental Safety, 68, 305-313. http://dx.doi.org/10.1016/j.ecoenv.2006.11.001

[35] Lasat, M.M., Fuhrmann, M., Ebbs, S.D., Cornish, J.E. and Kochian, L.V. (1998) Phytoremediation of a Radiocesium-Contaminated Soil: Evaluation of Cesium-137 Bioaccumulation in the Shoots of Tree Plant Species. Journal of Environmental Quality, 7, 165-169. http://dx.doi.org/10.2134/jeq1998.00472425002700010023x 
[36] Jarvis, M.D. and Leung, D.W.M. (2001) Chelated Lead Transport in Chamaecytisus proliferus (L.f.) Link ssp. Proliferus var. palmensis (H. Christ): An Ultrastructural Study. Plant Science, 161, 433-441. http://dx.doi.org/10.1016/s0168-9452(01)00424-1

[37] Wang, X., Liu, Y.G., Zeng, G.M., Chai, L.Y., Song, X.C., Min, Z.Y. and Xiao, X. (2008) Subcellular Distribution and Chemical Forms of Cadmium in Bechmeria nivea (L.) Gaud. Environmental and Experimental Botany, 62, 389-395. http://dx.doi.org/10.1016/j.envexpbot.2007.10.014

[38] Allen, D.L. and Jarrell, W.M. (1989) Proton and Copper Adsorption to Maize and Soybean Root Cell Walls. Plant Physiology, 89, 823-832. http://dx.doi.org/10.1104/pp.89.3.823

[39] Qiu, Q., Wang, Y.T., Yang, Z.Y. and Yuan, J.G. (2011) Effects of Phosphorous Supplied in Soil on Subcellular Distribution and Chemical Forms of Cadmium in Two Chinese Flowing Cabbage (Brassica parachinensis L.) Cultivars Differing in Cadmium Accumulation. Food and Chemical Toxicology, 49, 2260-2267. http://dx.doi.org/10.1016/j.fct.2011.06.024

[40] Chen, G.C., Liu, Y.Q., Wang, R.M., Zhang, J.F. and Owens, G. (2013) Cadmium Adsorption by Willow Root: The Role of Cell Walls and Their Subfractions. Environmental Science and Pollution Research, 20, 5665-5672. http://dx.doi.org/10.1007/s11356-013-1506-3

[41] Zhu, Q.H., Huang, D.Y., Liu, S.L., Luo, Z.C., Rao, Z.X., Cao, X.L. and Ren, X.F. (2013) Accumulation and Subcellular Distribution of Cadmium in Ramie (Boehmeria nivea L. Gaud.) Planted on Elevated Soil Cadmium Contents. Plant, Soil \& Environment, 59, 57-61.

[42] Su, Y., Liu, J.L., Lu, Z.W., Wang, X.M., Zhang, Z. and Shi, G.G. (2014) Effects of Iron Deficiency on Subcellular Distribution and Chemical Forms of Cadmium in Peanut in Relation to Its Translocation. Environmental and Experimental Botany, 97, 40-48. http://dx.doi.org/10.1016/j.envexpbot.2013.10.001

[43] Gallego, S.M., Pena, L.B., Barcia, R.A., Azpilicueta, C.E., Iannone, M.F., Rosales, E.P., Zawoznik, M.S., Groppa, M.D. and Benavides, M.P. (2013) Unravelling Cadmium Toxicity and Tolerance in Plants: Insight into Regulatory Mechanisms. Environmental and Experimental Botany, 83, 33-46. http://dx.doi.org/10.1016/j.envexpbot.2012.04.006

[44] Xu, D., Chen, Z., Sun, K., Yan, D., Kang, M. and Zhao, Y. (2013) Effect of Cadmium on the Physiological Parameters and the Subcellular Cadmium Localization in the Potato (Solanum tuberosum L.). Ecotoxicology and Environmental Safety, 97, 147-153. http://dx.doi.org/10.1016/j.ecoenv.2013.07.021

[45] Kovačević, G., Kastori, R. and Merkulov, L. (1999) Dry Matter and Leaf Structure in Young Wheat Plants as Affected by Cadmium, Lead, and Nickel. Biologia Plantarum, 42, 119-123. http://dx.doi.org/10.1023/A:1002135913249

[46] Lai, H.Y. (2015) Effects of Leaf Area and Transpiration Rate on Accumulation and Compartmentalization of Cadmium in Impatiens walleriana. Water, Air, \& Soil Pollution, 226, 2246. http://dx.doi.org/10.1007/s11270-014-2246-9

[47] Liu, J.G., Qian, M., Cai, G.L., Yang, J.C. and Zhu, Q.S. (2007) Uptake and Translocation of Cd in Different Rice Cultivars and the Relation with Cd Accumulation in Rice Grain. Journal of Hazardous Materials, 143, 443-447. http://dx.doi.org/10.1016/j.jhazmat.2006.09.057

[48] Hsu, Y.T. and Kao, C.H. (2003) Role of Abscisic Acid in Cadmium Tolerance of Rice (Oryza sativa L.) Seedlings. Plant, Soil \& Environment, 26, 867-874. http://dx.doi.org/10.1046/j.1365-3040.2003.01018.x

[49] Wang, W.X. and Rainbow, P.S. (2006) Subcellular Partitioning and the Prediction of Cadmium Toxicity to Aquatic Organisms. Environmental Chemistry, 3, 395-399. http://dx.doi.org/10.1071/EN06055

[50] Martin, C.A., Luoma, S.N., Cain, D.J. and Buchwalter, D.B. (2007) Cadmium Ecophysiology in Seven Stonefly (Plecoptera) Species: Delineating Sources and Estimating Susceptibility. Environmental Science \& Technology, 41, 71717177. http://dx.doi.org/10.1021/es071205b

[51] Kamunde, C. (2009) Early Subcellular Partitioning of Cadmium in Gill and Liver of Rainbow Trout (Oncorhynchus mykiss) Following Low-to-near-Lethal Waterborne Cadmium Exposure. Aquatic Toxicology, 91, 291-301.

http://dx.doi.org/10.1016/j.aquatox.2008.10.013 